\title{
LAS AYUDAS A LA PRENSA EN ESPAÑA
}

\section{Alfonso de la Quintana: Universidad Rey Juan Carlos (España)}

\section{Introducción}

Históricamente todos los gobiernos han dedicado una parte de sus presupuestos para ayudar a los medios de comunicación en el desarrollo de su quehacer empresarial. Esta relación empresarial existe casi desde que los medios nacieron. Pero en realidad es un peligro para la independencia de los medios, aunque también una necesidad para la supervivencia de los mismos. Una ecuación difícil de cuadrar. Ya que sin dinero muchos pequeños medios morirían ante las distintas crisis y carestías que deben soportar y la opinión pública hubiera perdido independencia, al perder un medio.

Por otro lado, esta concesión económica es muy difícil que se pueda entender sin que sea a cambio de algo por parte del gobierno de turno. Lo que ha supuesto que este tipo te ayudas empresariales hayan entorpecido mucho más el sistema democrático basado en la transparencia. Porque al tratarse de empresas de opinión, tienen una influencia en la opinión pública difícilmente cuantificable. Es muy difícil cuantificar la rentabilidad de influencia en la opinión pública de un medio importante de comunicación. Baste decir que con ellos se ganan y se pierden las elecciones. Por ello las empresas periodísticas deben ser ejemplares en la transparencia de las ayudas recibidas. Para solucionar este problema los gobiernos han promulgado distintas leyes.

El profesor Tallón señala claramente dos posturas académicas respecto si son necesarias las ayudas a las empresas. Son la escuela la proteccionista y la liberal. Aunque con el paso del tiempo si bien se ve un decaimiento de la proteccionista, alimentada principalmente por los antiguos países comunistas, también hay un resurgimiento muy integrista de las liberales, que a veces sobrepasan al integrismo más capitalista. Es la escuela de: El dinero por el dinero y sin dinero no existe nada. Todo lo que sea privatizar es lo bueno, lo público es negativo. La calidad41es propiedad de lo privado. Parece que se basaran en: "El egoísmo humano lleva a que todo funcione mejor por su propio beneficio". Desgraciadamente es una gran verdad. Sobre todo si el egoísmo es de una sola persona o grupo empresarial.

a) La Proteccionista: es propia de países del antiguo bloque comunista o de países en vía de desarrollo. En estos países, el Estado debe de asumir los gastos de muchas empresas. En otros se ha llegado a basar su intervención en la función social de la misma ya que los empresarios no invertían en esos negocios. Las causas de esta escuela se basan en lo que expone Tallón:

"El aumento acelerado e imparable de los costes, el escaso incremento de la difusión, la competencia creciente de otros medios informativos, deficiente 
gestión empresarial, el progresivo desfase entre el aumento de ingresos por ventas y de nos costes".

b) La Liberal: Es el modelo más difundido en los Estados Unidos y ampliado hasta los límites por la escuela económica neoliberal. Se basa en que la ley de la oferta y la demanda es la que debe de regir la vida económica de la empresa. Habría que matizar que últimamente esta escuela se aprovecha de lo público para hacerlo privado con la excusa de la reducción de costes pero con servicios peores. Dándose casos en los que se privatiza lo público y lo c) privado se hace público según convenga a los gobiernos de turno.

En líneas generales esta escuela nos dice que la intervención del estado en las empresas es un peligro, ya que la empresa puede vivir de un modo ficticio incluso se puede primar la mala gestión empresarial. Un ejemplo de empresa periodística protegida sería el diario Pravda, fundado por Lenin que llego a publicar 13 millones de ejemplares. Pero cuando se abre la Unión Soviética a la libertad de mercados sus actuales propietarios unos editores griegos lo cierran alegando la falta de disciplina de sus trabajadores y al alto nivel de alcoholemia de los mismos. Además los trabajadores estaban acostumbrados a recibir primas por cada información publicada No se diferenciaba la noticia de la publicidad. Este periódico fundado en 1912 en su última etapa no ha superó unas decenas de miles de ejemplares vendidos a los pocos comunistas nostálgicos que quedaban en Rusia. Este periódico que fue capaz de soportar 12 cierres durante la etapa zarista, no pudo superar la libre competencia. Pero la puntilla para el Pravda se produjo cuando el Gobierno de Yeltsin subvencionó el papel un 30\% a los periódicos que el Ministerio de Información de Rusia decidiera arbitrariamente y que las fábricas no subieran el precio del papel, por supuesto el Pravda no estaba en la lista de los subvencionados.

La última ley de ayudas a la prensa españolas está claramente influenciada por la normativa francesa. En Francia, antes de elaborar la ley, el gobierno encargó tres informes para analizar si el gobierno debía ayudar a la prensa. Estos son:

1) Serisé, de julio del año 1972. Aportó conclusiones como que: "la principal razón de la ayuda del estado a la prensa es de orden político, en su sentido más noble. Se trata de favorecer la existencia de diarios que representen diversas corrientes de opinión y les permitan participar en la vida pública. Si el objeto de la ayuda es la comunicación del pensamiento a través de los periódicos, y si el beneficiario final es el lector, el adjudicatario inmediato de la ayuda es casi necesariamente la empresa periodística, a cuya costa se hace posible que el lector pueda adquirir diario a un precio inferior al de coste, 0 bien le permita mejorar su contenido".

2) Drancourt febrero del año 1974. Sus conclusiones son más pragmáticas que el anterior y nos aporta ideas como que: "El fin de la ayuda no debe de ser cubrir las deficiencias de la gestión empresarial, sino garantizar el derecho i la información para todos y la libertad de expresión de todos los ciudadanos. La 
ayuda debe de responder a dos exigencias. 1․ Asegurar la liberta de expresión y mantener la pluralidad de los órganos de prensa. $2^{\circ}$. Promover los medios materiales y la aplicación de técnicas y métodos modernos a la empresa periodística en todos los niveles para garantizar su futuro, ante el desarrollo de la comunicación audiovisual.

El informe Drancourt del año 1974, es el que más ha inspirado la ley española. Este informe francés es interesante al aportar que el Estado no debe de cubrir la mala gestión empresarial, y que la función de las ayudas del Estado a la Prensa es la de garantizar el derecho a la información y la libertad de expresión.

Hay que señalar que si el Estado cada vez que naciera una nueva tecnología que amenazase a los periódicos tuviera que establecer una ayuda, además de ser muy costoso por la continua revolución tecnológica, sería un agravio comparativo para los demás medios de comunicación.

3) Vedel del año 1979. Nos dice sobre la ayudas que: "Una ayuda específica debe de poder ser aceptada, no para los periódicos sin lectores, sino para los diarios que, aunque tengan un público, no constituyan técnicamente un soporte interesante para los distribuidores de publicidad" "No es el Estado el que tiene en sus manos el destino de la prensa francesa: es la propia prensa".

\section{Clasificación de las ayudas}

En líneas generales las ayudas del estado a la prensa se pueden clasificar en:

1. Directas: aquellas que suponen un ingreso inmediato en la caja de la empresa.

- Reducción de las tarifas postales, telegráficas y telefónicas.

- Subvención a empresas periodísticas para la adquisición de papel prensa.

- Créditos oficiales de carácter privilegiado.

- Subvenciones para la renovación de maquinaria.

- Exoneración de impuestos y tasas.

- Contratación de espacios publicitarios de interés general, la llamada publicidad institucional.

2. Indirectas: aquellas cuyo beneficio recae de una manera indirecta en la empresa. Pero siendo esta beneficiaria indirecta de ese beneficio. Serían las ayudas que son destinadas a los trabajadores, a las empresas afines a las periodísticas (como las papeleras, imprentas, distribuidoras).

- Subvenciones a los fabricantes de papel-prensa.

- Estímulos económicos a los fabricantes de maquinarias de artes gráficas.

- Beneficios económicos a favor de todos los trabajadores de la empresa periodística.

- Subvenciones a instituciones corporativas de la prensa. 
- Reducción de los costes de los servicios de agencias de noticias nacionales, ya que reciben una ayuda del estado.

- Promoción de servicios comunes distribución y ayuda económica a los canales de distribución.

- Realización de estudios económicos y financieros sobre la prensa.

\section{El caso español: evitar la picaresca...}

La situación actual para las empresas periodísticas es de total desconcierto pues en el caso español nos regimos por la Ley de 1984 que está vigente pero que ya se dejó de aplicar durante la etapa socialista en el año 1989.

Para algunos, el que se dejara de aplicar esta ley ha sido puesto como un ejemplo del: "momento cumb2e del poder socialista en España, la subrepticia comisión liquidadora encabezada por el guerrista Francisco Virseda pudiendo suprimir todo vestigio de ayuda a la canallesca sin que el conjunto de la Prensa española elevase sus gritos al cielo" (29-11-96 El Mundo, Víctor de la Serna).

Para otros lar ayudas del Estado no tienen por qué existir y sus máximos defensores son los representantes del grupo PRISA. A la cabeza con Jesús Polanco que se manifestó en el año 96 "absolutamente" contrario a cualquier tipo de ayuda, añadiendo "que bendita la prensa que no recibe la ayuda de ningún Estado" o matizando que "la prensa vive sola o se muere" y que "el mundo moderno es un mundo de mercado y de empresas modernas".

Ante esta situación la AEDE (Asociación de Editores de Diarios Españoles) mantuvo relaciones con "el Gobierno del PP pero solo se llegaron a buenas intenciones como:

a) Crear una Comisión compuesta por editores y representantes de tres Ministerios para estudiar la forma de ayudar a las empresas periodísticas.

b) Entre esas ayudas estaría la rebaja del IVA a cero y la reducción de tarifas de telecomunicaciones.

El mismo José María Aznar se comprometió a estudiar posibles "prestaciones" relacionadas con el precio del papel prensa, las transmisiones de datos, la distribución y la reducción del IVA. Hasta la fecha nada de nada.

Por otro lado el Gobierno de Aznar no aceptó la crítica de la doble financiación de la televisión estatal alegando su portavoz, que "Desde que comenzó la crisis en 1991 se ha mantenido estable la inversión publicitaria en televisión con unos 225.000 millones de pesetas, y en Prensa, con 180.000 millones de pesetas".

Este sería el contexto en el que nace esta ley de ayudas del estado a la prensa. 
Esta ley del año 84 es muy interesante ya que comienza a detallar y estudiar muy específicamente las ayudas. Es el caso de ayudar a los periódicos de reciente creación con una ayuda muy determinada. $Y$ en todo caso exigiendo (Art. 4) unos requisitos más elaborados que se verán en los posteriores artículos (Art.5, 6, 7,8).

El espíritu principal de esta Ley es evitar el fenómeno de la concentración de medios de información, que ya en aquellos años se estaba produciendo y que en la actualidad no para de crecer. Por ello, esta ley intenta fomentar el pluralismo informativo. Ayudando a las pequeñas empresas periodísticas con menos ventas y favoreciendo la creación de nuevos periódicos. También se ayuda a las empresas que tienen una difusión internacional.

Finalmente lo verdaderamente transcendental de esta ley es la aplicación de la ANTIPICARESCA. Se dan ayudas pero se han de justificar sus gastos. Sean ante notario las facturas, no puede ser deudor de la Seguridad Social ni de Hacienda, las inversiones deben permanecer en los medios y ser dirigidas hacia ese sector. Se exigen contraprestaciones, no son a saco roto. Estas ayudas son:

1. Las ayudas directas son: Ayudas por difusión, por consumo de papel prensa y por reconversión tecnológica.

Curiosamente a las agencias informativas solo podían solicitar la ayuda por reconversión tecnológica. Cuando son también una empresa periodística.

- Ayudas por difusión:

Se otorgaba esta ayuda basándose en la difusión demostrada del año anterior ante organismo con credibilidad como la OJD.

Se daba una ayuda complementaria a las empresas situadas en Ceuta, Melilla, Baleares, Canarias por su singularidad geográfica. Este apartado es muy importante. Se está contemplando la rentabilidad de influencia de los medios en algunos territorios. Se están fomentando medios de comunicación para crear opinión pública frente a posibles situaciones de antiespañolismo. Estrategia nada nueva y que se puede observar en zonas como Gibraltar donde la prensa nacionalista británica es abrumadora por su variedad.

Continua aportando la ley que también recibirán una ayuda las empresas periodísticas que editen un en territorio español y que lo difundan en el extranjero al menos una vez a la semana. (Difusión o exportación de ejemplares). Otra medida claramente política para fomentar el uso del español. Podríamos tomar como referencia el papel de la BBC para la difusión el inglés en el mundo.

Cabe señalar dos puntos importantes en esta ley: 
a. Que si cuando se solicita la ayuda la empresa periodística tiene alguna duda con Hacienda Pública, Seguridad Social o instituciones oficiales de crédito, la administración aplicara el pago de esas deudas sobre la ayuda otorgada.

b. Si los contenidos publicitarios publicados el año anterior superan el $50 \%$ del espacio de la publicación, con exclusión de los suplementos. El porcentaje de la ayuda se reducirá en un porcentaje igual al doble del porcentaje en exceso.

Estos dos puntos son un ejemplo de las muchas medidas anti-picarescas que tiene esta ley.

- Ayudas por consumo de papel-prensa nacional:

La ayuda es de pesetas por kilo de papel prensa nacional consumida. Que no comprado. Es muy fácil comprar y repartir. Lo difícil es imprimir y vender el ejemplar.

Se considera papel prensa "el papel blanco o ligeramente teñido en la pasta que contenga un $70 \%$ o más de pasta mecánica, cuyo índice de alisado, medido en el aparato Bekk, no exceda de 130 segundos, sin encolar, que se presente en bobinas de $31 \mathrm{~cm}$. De anchura como mínimo y, que no contenga en peso más de $8 \%$ de cargas"

La ayuda se justificará aportando la factura de los proveedores de papel prensa y declaración notarial del empresario expresiva del consumo papel-prensa nacional.

Este apartado de la ley al entrar España en la U.E fue derogado pues suponía una transgresión del principio de no discriminación por motivo de nacionalidad, contemplado en el art. 7 del Tratado de la CEE, en relación con el 52 del mismo. Lo que significa que hay que comprar papel en otros países de Europa donde es más barato y de mejor calidad.

Además no se puede proteger la industria nacional a cuenta de perjudicar a la industria de otro miembro de la U.E.

- Ayuda por la reconversión tecnológica:

Desde los años 80 las innovaciones tecnológicas han afectado a todas las empresas y especialmente a las informativas, Esto ha supuesto pagar un alto precio para poderse apuntar a las innovaciones tecnológicas. El precio no solo ha sido económico sino también humano. Muchos fueron los trabajadores que fueron despedidos con la aparición de las maquinas, principalmente el personal de talleres. Quedando borrado del mapa laboral el gremio de los linotipistas. Curiosamente un gremio con una lata tasa conflictividad laboral. 
Pero esta carrera de los años 80 por la tecnología no ha acabado, con lo que continuamente se producen regulaciones de empleo como el caso de ABC y del $\mathrm{Ya}$ en los años 80. También en el año 94 fuera de nuestras fronteras al New York Times le supuso su saneamiento un gasto de 30 millones de dólares.

Ante este panorama tan crítico, tanto el Estado como las empresas vieron la necesidad de que existieran ayudas para que las empresas tuvieran lo último en tecnología.

Son las ayudas destinadas a las empresas informativas que realizaban la reconversión tecnológica.

Los equipos a los que van destinado este tipo de ayuda, que contempla la ley del 84 , son:

- Equipo de fotocomposición y mecánica.

- Rotativas.

- Equipos de cierre.

- Sistemas de tratamiento informático.

- Equipos de transmisión instantánea.

Si los bienes adquiridos por estas empresas a través de una ayuda son enajenados ates de 5 años desde su adquisición, la empresa beneficiaria se verá obligada a devolver la ayuda. Otro ejemplo de medida antipicaresca. Para evitar la venta de material a terceros.

- Ayuda especial a nuevos periódicos diarios:

Es una ayuda especial de una sola vez, se otorga en el ejercicio presupuestario siguiente a de la aparición del diario. Si se dieran inmediatamente se podía caer en la tentación de fundar muchos periódicos durante menos de un año y cobrar sus respectivas ayudas. Si haber producido ningún beneficio a la sociedad.

Finalmente hay un grupo de ayudas que se centran en las de tipo tributario, crediticio, postal, de distribución y de comunicación. Serían los créditos más baratos, menor pago de impuestos, menor gasto de correos. Este gasto último, posiblemente, con las nuevas tecnologías como Internet desaparezca en su mayoría.

2. Las ayudas indirectas. Son las que no van directamente a la caja de las empresas informativas. Van a sectores muy afines.

Es muy positivo que esta ley no beneficiaba solo a las empresas periodísticas, sino también a muchas empresas que tienen una estrecha relación como son las empresas editoras de publicaciones no diarias de información general. 


\section{El futuro de la ayudas a la prensa}

La tendencia es ir a un mercado cada vez más neoliberal o de capitalismo integrista. Lo que posiblemente harán desaparecer todo tipo de ayudas a la prensa. Y sean los propios grupos empresariales los que mantengan a los medios según su conveniencia.

Pero en la actualidad la ayuda que tiene más futuro es la Publicidad Institucional. Un ejemplo de su importancia sería citar, en el caso español, el Diario El Alcázar, por ser un ejemplo de discriminación de publicidad institucional - si consideramos esta publicidad, una forma de ayuda- por parte del Gobierno (PSOE), y como luego hubo de dar el Estado una indemnización por sentencia, lo que supuso un coste para todos los ciudadanos. Además este caso puede aportar jurisprudencia ya que hay Sentencia del Tribunal Supremo, sobre la discriminación de publicidad, y de la Audiencia Nacional (Sentencia de Enero de 1988, a pagar 12 millones de pesetas "derivado de un actuar de la Administración contrario a la Constitución, por discriminatorio").

No le faltó tiempo al diario El Mundo del 18 de Noviembre de 1994, a gritarlo a los cuatro vientos: "El Estado deberá pagar a los dueños del Alcázar 3.000 millones por discriminarle la publicidad institucional”.

La publicidad institucional no solo ha planteado polémicas con el difunto diario El Alcázar, sino con publicaciones recientes como El Mundo. Que en el año 94 realizaba un estudio a partir de los datos de la empresa de Publicidad Duplo. En el que se aportaban los siguientes datos para demostrar la discriminación publicitaria, que el entonces Gobierno Socialista hacía con algunos medios. Quedaba de la siguiente manera: El País acaparaba el $28,6 \%$ del total invertido en seis diarios de información general de mayor difusión; por el 17\% ABC, el 16\% de El Mundo, 13,6\% de Diario 16 y el 12,5\% La Vanguardia. En el año 1993 IBERIA invirtió 59,2 millones de pesetas en poner publicidad en el diario El País. La cifra contrasta con los 27 invertidos en ABC, los 20,7 en La Vanguardia o los 10 en El Mundo. La Dirección General de Tráfico puso anuncios en El País por 50,1 millones de pesetas, cantidad notablemente superior a la invertida en El Mundo (19,4 millones); $\operatorname{ABC}(10,4$ millones).

Respectos al medio radio El Organismo nacional de Loterías y Apuestas del Estado puso anuncios en la cadena SER por 1.101 millones de pesetas, cifra que multiplica a la que invirtió en la COPE (230 millones) y Onda Cero (183,7 millones).

Hay Comunidades Autónomas que solo invierten en los medios más cercanos geográficamente. La Comunidad de Madrid que presidía Joaquín Leguina invirtió 531 millones en anunciarse en su propia televisión, frente a 1,8 millones en TVE, 0,6 
millones en Telecinco; y 12,8 en Antena 3tv. Otro ejemplo según este informe sería el de La Generalitat que puso anuncios por valor de 1.005,6 millones en TV3 pero no se anunció en las televisiones privadas, y solo invirtió 4,9 millones en TVE. Según los datos de este informe existiría una fuerte discriminación de publicidad institucional, lo que podría afectar a la independencia de los medios.

Señalar que este informe no coincide con algunas interpretaciones de autores como Xabier Oliver en su libro "La Publicidad en la Administración Española" que dice "no conocer ningún caso de enchufismo, solo intuiciones".

Lo cierto es que mientras se anuncien con tan poco tiempo los concursos de las campañas de publicidad no todos podrán competir en igualdad. A fecha de 18 de mayo de 1999 el Congreso rechazaba regular la publicidad institucional.

Legislaciones autonómicas de las ayudas a la prensa.

Se habla de las ayudas del estado español a la prensa. Pero pocas veces se estudian y se ponen en conocimiento las ayudas que dan estos microestados, llamados autonomías, a los medios de su entorno político o cultural.

Un ejemplo serían las siguientes leyes autonómicas de ayudas a la prensa.

- Ley Catalana de 16 de Octubre de 1995.

- Ley Vasca de 17 de Abril de 1997.

- Ley Gallega de 19 de Septiembre de 1996.

En la legislación Autonómica se dan tres órdenes: Cataluña, Euzkadi, Galicia. Siendo la orden de Euzkadi la más amplia. Y en todas ellas se potencia el uso de la lengua de cada Comunidad para dar la ayuda a los medios, no solo en la prensa escrita sino en medios como la radio.

La subvención más elevada de todas las comunidades es la de Euzkadi: 198.100.000 ptas. (Art.1), que se dividirá entre los distintos tipos de publicaciones que da la ley: prensa diaria, Semanarios, Revistas infantiles, Revistas que tengan una distribución de un $25 \%$ fuera de Euzkadi (Art.3d). Teniendo siempre como requisito a las publicaciones estar redactada íntegramente es euzkera (Art.4). Es interesante el tratamiento que da la orden a las publicaciones de carácter infantil y pedagógico con una ayuda a repartir de 13.100 .000 ptas. (Art. 3c).

Es curioso que hagan referencia a las publicaciones infantiles. Pero la lógica es fomentar este tipo de publicaciones para que el mayor número de menores hable euskera.

La orden de Cataluña, tiene un fuerte componente lingüístico ya que insiste que el sentido de esta ley es la "normalización lingüística progresiva", y todos sus apartados se centran en difundir el catalán. 
La orden gallega, destaca que se excluyen de las ayudas a: los boletines internos de las instituciones, la prensa de los partidos políticos, y a la prensa gratuita (Art.2). Y pone como requisitos el uso de la lengua gallega, la tirada de ejemplares y el número de lectores u oyentes (Art.8). El total de la ayuda de la comunidad gallega es de 150 millones de ptas. (Art.3). Esta ley gallega tiene que volver a la antipicaresca evitando que hasta los boletines de las empresas puedan tener ayudas.

\section{La situación en otros países}

En el año 1992 el Parlamento Europeo pidió ayudas a las autoridades de la Comunidad Europea, para evitar la concentración de medios. Este informe fue realizado por el eurodiputado socialista Ben Fayot y llegaba a conclusiones como que los procesos de concentración de empresas informativas se están produciendo: "sin límites ni control en el sector de los medios de comunicación lo que constituye un peligro para el derecho a la información y a la libertad de los periodistas" por lo que pidió urgentemente a la Comisión Europea que elaborara de forma urgente una propuesta de legislación antimonopolio. Pues la actual normativa comunitaria de fusiones no puede suplir la falta de legislación sobre los medios. Esto supuso, según los propios parlamentarios, que dicha propuesta fuera retirada la orden del día en el Parlamento Europeo debido a las presiones de varios eurodiputados próximos al magnate de la prensa Silvio Berlusconi. Otro ejemplo de relación empresa-Gobierno. $Y$ de lo que les gusta a los políticos y grupos empresariales la rentabilidad de influencia de los medios de comunicación.

Este informe señalaba que desde 1967 en Europa han desaparecido el 20\% de los diarios y entre los pises más afectados están: España, Francia, Gran Bretaña y Bélgica y la mayoría de estos periódicos han pasado a formar parte de los grupo multimedia liderados por Hersant, Hachette, Berlusconi o Springer.

El profesor Tallón señalaba que en Europa los países que más se han interesado en ayudar a la prensa son:

- Suecia

Es uno de los países que más interés ha mostrado por realizar una serie de medidas que ayuden a la prensa. Esto es debido a que este país ha sufrido los índices de mortandad de los periódicos es uno de los más elevados del mundo. Baste decir que desde 1950 de 250 pasaron a ser 146. Y el número de ciudades que contaba con un diario descendió de 51 a 20.

Para solucionar esta situación el Gobierno sueco decidió ayudar a las empresas reduciendo impuestos y tasas de servicios. En 1965, 1969, 1971 reaccionaron otorgando préstamos y "subvenciones a la producción" para los periódicos de poca circulación. Peor las medidas no solucionaban la crisis y en el año 1976 se decide 
aprobar ayudas como: la de papel consumido, para los periódicos que se publiquen de uno a tres días por semana, otra ayuda para los periódicos que publiquen los siete días, ayuda para la fundación de hojas complementarias en la forma de préstamo sin interés, para diarios no nacionales que aparezcan de uno a tres días a la semana, otra ayuda a los diarios nacionales, ayuda para la distribución conjunta, apoyo a las cooperativas, ayudas a los proyectos interempresariales, crear una caja de préstamo.

En la actualidad el mayor grupo de población de este país está entre los $2 \mu$ y 44 años con lo que será una población vieja dentro de pocos años.

En la actualidad el número de cabeceras se aproxima al centenar con la ventaja de que al ser un país del norte la mayoría de los lectores son suscriptores y eso es una ventaja competitiva respecto a los países de sur de Europa que no tiene gran cantidad de suscriptores.

\section{- Alemania}

Desde al año 1950 las publicaciones han descendido de 755 a 364 . A pesar de la Crisis en los diarios es en estos años cuando se hace más fuerte el famoso Grupo Axel Springer. Entre los años 1974 y 1976 los ingresos por publicidad descendieron en un $50 \%$ que junto a la constante subida del precio del papel la continua subida de los carburantes la supervivencia de loó periódicos era casi imposible.

Para ello el Gobierno alemán creó en 1975 la Presse Stiftung o fundación de la prensa. Esta fundación administraría una caja de préstamos para los diarios. Esta iniciativa fue muy criticada por los grandes grupos especialmente por Springer que apoyaba más la idea de que se moderaran los gastos de servicios públicos. Mientras la Sociedad de Editores de Diarios Alemanes consiguió que se redujera el IVA, al $6 \%$ mientras que para las demás empresas era del $12 \%$.

- Gran Bretaña

Las ayudas por parte del Estado no son tan bien vistas como en otros países, y las empresas periodísticas británicas se niegan a aceptarlas. Además en este país la crisis-prensa ha sido más fuerte debido a que a la carestía del papel, de los carburantes, la crisis publicitaria hay que añadirle el papel intransigente de los sindicatos. No permitiendo una regulación de personal. Cuando existía en esos años 80 una abundante mano de obra en los periódicos británicos.

Tan grave fue el choque patronal prensa-sindicatos que en la actualidad son muchos los periódicos en los que su redacción está separada y bastante lejos de los talleres. Para evitar el contagio de reivindicaciones sociales como las "huelgas". El ejemplo más claro del poder que tenían los talleres frente a toda la plantilla, se demostró en 1986 cuando Murdoch trasladó cuatro de sus cinco periódicos, The Times, Sunday 
Times, The Sun y News of the World al este de Londres. Debido a la fuerte disputa que mantuvo con los sindicatos que se oponían a la introducción de pantallas de ordenador. Donde los periodistas escribirían sus informaciones, que irían directamente a fotocomposición, lo que supondría el fin de los linotipistas.

Esta guerra con los sindicatos en el Reino Unido la comenzó un empresario iraní, Eddy Shah, propietario de Today, y que contó con el apoyo escondido de la Primera Ministra Thatcher, que deseaba acabar con la fuerza de los Trade Union en Gran Bretaña. Y que fue el primero en introducir lo último en tecnología en las empresas periodísticas. Luego vino lo que vino.

Esto supuso que en la mítica Fleet Street en la actualidad solo quede la agencia de noticias Reuter y los pubs que eran frecuentados por los periodistas. Y esta era un mítica calle donde se producían la mayoría de los periódicos del Reino Unido.

Pero lo cierto es que los editores consiguieron la exención del IVA y utilizar el servicio postal clasificado en $1^{\text {a }}$ clase, pagando el de segunda. Ayuda esta última insuficiente pues solo el $1 \%$ de los periódicos británicos utiliza como distribuidora el correo. Si alguien consiguió algo, fueron los amigos de la superministra que promulgaba el capitalismo integrista.

- Francia

Para contentar a los periodistas se le concedió una deducción del 30\% en el impuesto sobre la renta.

Pero el Gobierno propuso suprimir esta ayuda indirecta. Lo que movilizó al colectivo de los periodistas franceses, unos 25.000 llegando éstos a intentar hacer presión sobre los diputados franceses que apoyasen esta iniciativa del Gobierno. Ante esto las autoridades respondieron que demandarían a los periodistas que utilizaran esta técnica. Un buen ejemplo e relaciones democráticas.

Lo cierto es que recientemente el Gobierno francés ha anunciado un aumento de las ayudas a la prensa en $3,2 \%$. Postura bastante lejana del caso español. $Y$ ayudas que de nuevo van a la caja de la empresa y no al bolsillo de los trabajadores.

\section{Referencias}

TALLÓN, J. Lecciones de Empresa Informativa. Ediciones de las Ciencias Sociales. Madrid, 1992.

OLIVER, X. La Publicidad en la Administración Española. Asociación Española de Agencias de Publicidad. Madrid, 1991. 


\section{ANEXO}

\section{Fuentes}

Se aporta información en la que la AEDE es muy favorable a las ayudas de Estado a la Prensa. El cambio de Gobierno no ha significado que las ayudas que en su día retiró el PSOE vuelvan con el PP a pesar de las continuas reuniones que ha mantenido la AEDE con el Gobierno (Mirar 20-11-96), en el que ha tenido un papel muy destacado por parte de AEDE, Pedro Crespo de Lara. (Mirar 19-11-96).

Destaca la posición de Polanco durante los últimos meses en los que defiende que la prensa no ha de tener ayudas (Mirar 23-11-96), en la que dijo que: "la prensa vive sola o se muere". Esta postura va en contra de la mayoría de los representante de AEDE, y en algunos sectores periodísticos se comenta que esta postura lo que realmente intenta es que los demás periódicos- para los que las subvenciones son vitales- cierren por faltas de ayudas mientras que las publicaciones de Polanco que no las necesiten sobrevivan.

\section{elpais.es}

\section{Edición impresa > sociedad}

http://www.elpais.es/articulo.html?xref=20011128elpepisoc_11\&type=Tes\&anchor=el pepisoc\&d_date=20011128" Anunciantes y agencias critican los concursos de la Administración.

La Asociación Española de Anunciantes (AEA) y la Asociación Española de Agencias de Publicidad (AEAP) denunciaron ayer 'las atrocidades' y 'el despilfarro' que está cometiendo la Administración a la hora de convocar concursos para la adjudicación de campañas publicitarias. Estas entidades calculan que el Gobierno central ha invertido en 2001 alrededor de 15.000 millones de pesetas, pero la mayor parte de los organismos públicos han seguido procedimientos indiscriminados y masivos, lo que provoca, en opinión de Francisco José González, presidente de la AEAP, 'un enorme perjuicio' al sector publicitario, a las agencias y al bolsillo de los ciudadanos. Son mecanismos 'especialmente dañinos' en momentos de recesión económica como el actual, apuntó Rafael Mazón, presidente de la AEA.

La convocatoria del Ministerio de Medio Ambiente para la adjudicación de una campaña promocional de alrededor de 4.000 millones de pesetas es un ejemplo de estas prácticas 'nocivas'. 